\title{
MISIÓN CALEB Y SU EFECTO EN EL NIVEL DE COMPROMISO MISIONERO DE JÓVENES EN LA ZONA NORTE DEL PERÚ
}

\author{
Enzo Rónald Chávez Hidrogo \\ enzoronald@hotmail.com \\ Universidad Peruana Unión \\ Juan Marcelo Zanga Céspedes \\ marcelozanga@teologia.edu.pe \\ Universidad Peruana Unión
}

El propósito que persigue esta investigación es determinar el efecto del proyecto "Misión Caleb" en el compromiso misionero de los jóvenes en la zona norte del Perú.

No existe un trabajo que evalúe el impacto del proyecto "Misión Caleb", en los jóvenes en la zona norte del Perú. Este trabajo permitirá crear instrumentos que ayudarán a evaluar el proyecto, también será base para la realización de futuras investigaciones en esta área. En el área práctica, esta investigación puede ayudar a los pastores distritales, administradores, departamentales, ancianos, dirigentes de iglesias y grupos pequeños para el mejoramiento del proyecto en sus respectivos niveles de trabajo misionero, con los jóvenes y con el resto de miembros de la iglesia.

La metodología para abordar esta investigación será descriptiva, exploratoria, de diseño no experimental y de corte transversal. Se tomó una muestra probabilística de 341 participantes en "Misión Caleb".

Los resultados indican que el proyecto "Misión Caleb" afecta positivamente el nivel de compromiso misionero de los jóvenes, en el territorio de la zona norte del Perú.

Palabras clave: Misión Caleb, compromiso misionero. 


\section{CALEB MISSION AND ITS EFFECT ON THE LEVEL OF MISSIONARY YOUTH COMMITMENT IN THE NORTH OF PERU}

\section{Abstract}

The purpose pursued by this research is to determine the effect of "Caleb Mission" project in the missionary commitment of young people in the north of Peru.

There is no researchers to assess the impact of the "Mission Caleb" in young people in the north of Peru. This work will create tools to help evaluate the project, it will also, being the basis for conducting future research in this area. In practice, this research can help the pastors, administrators, dean departmental, elders and leaders of churches and small groups in the improvement project at their respective levels of missionary work with young people and other members of the church.

The methodology for this research will address descriptive, exploratory, non-experimental and cross-sectional design. A probability sample of 341 participants "Caleb Mission" took.

The results indicate that "Caleb Mission" project positively affects the level of missionary commitment of young people in the territory of the north of Peru.

Keywords: Caleb Mission missionary commitment. 


\section{Introducción}

La participación de los miembros de la Iglesia, en el compromiso misionero, es necesaria en la vida cristiana. Algunos autores como McNeal, Kidder, Blackaby, Schwarz, Dick y Willard ${ }^{1}$ unen la necesidad de una vida espiritual saludable con el trabajo misionero, en forma de ministerios, como actividades inseparables. Entonces, las actividades que se desarrollen en la Iglesia deberían ayudar a desarrollar el compromiso misionero y deben tener el propósito de estimular, desarrollar y fortalecer la comunión del miembro de iglesia con Dios, por medio de la práctica de las disciplinas espirituales.

${ }^{1}$ MReggie McNeal. A Work of Heart: Understanding How God Shapes Spiritual Leaders. San Francisco: JosseyBass Pub., 2000; Joseph Kidder. Majesty: Experiencing Authentic Worship. Hagerstown MD: Review and Herald Pub., 2009; Henry T. Blackaby. And Claude V. King. Experiencing God. Nashville: Broadman and Holman, 1998; Christian Schwarz. The 3 Colors of Ministry. Saint Charles, IL: ChurchSmart Resources, 2001; Dan R. Dick y Barbara Miller. Equipped for Every Good Work. Nashville: Discipleship Resources, 2001; Dallas Willard. The Divine Conspiracy. San Francisco: HarperCollins, 1997.
Para estimular actividades misioneras en la Iglesia adventista se desarrollan diferentes programas regulares como cultos y programas evangelisticos en semanas especiales, reuniones de grupos pequeños, minutos de motivación durante la escuela sabática, mediante sermones en el culto divino y en el culto joven entre otros. Sin embargo, también se ha desarrollado programas no regulares como los programas con énfasis en evangelismo público. Ambos, los programas regulares e irregulares, tienen el objetivo de involucrar a los miembros en la acción misionera.

Algunos datos indican que el trabajo misionero, desarrollado por los miembros de la iglesia, es bajo y limitado en todos los campos misioneros. A nivel mundial, entre los años 1997 y 2012, el número de miembros involucrados en la acción misionera ha descendido de 9 a 6 de cada $100^{2}$;

${ }^{2}$ Tomando en cuenta los datos estadísticos de la Conferencia General de la IASD entre los años 1997 y 2012, y suponiendo que cada miembro de la iglesia, como parte de su compromiso cristiano, ganó un nuevo miembro cada año, el número de miembros debía multiplicarse. 
en Sudamericana, en esos mismos años el promedio se ha mantenido en $10^{3}$ con un leve crecimiento para el 2012 a 11, finalmente en la zona Norte del Perú el comportamiento misionero ha fluctuado entre 6 y 8 entre los años 2007 y 2011, mientras que en el año 2012 ha subido a $13 .{ }^{4}$ Si se entiende

A nivel mundial entre los años 1997 y 2001 un promedio de 9 personas estaban involucradas en el trabajo misionero, entre los años 2002 y 2007 esa cantidad bajó entre 7 y 8 , finalmente, entre los años 2008 y 2012 el promedio es de 6 miembros involucrados en la acción misionera. Seventh-day Adventist world Statistic (2012). http://www.adventiststatistics. org/view_Summary.asp?FieldAbr=GC consultado el 12 de agosto de 2014.

${ }^{3}$ Los datos del crecimiento de la División Sudamericana presenta una pequeña variación, entre los años 1997 y 2001, indican una ligera variación entre 9, 811 y 10 , mientras que para los años 2002 y 2007 el promedio fluctuó entre 11, 12, 9 y 8, finalmente, para los años 2008 al 2012 los promedios subieron entre 7, 9 y 10. http://www. adventiststatistics.org/view_Summary. asp?FieldID=D_SAD\#main consultado el 25 de agosto de 2014.

${ }^{4}$ En la zona norte del Perú el compromiso misionero tenía un promedio de 6 en el 2007, mientras que para el 2008, 2010, y 2011 el promedio subió a 8 , finalmente el promedio de compro- que solo entre 6 y 13 personas están involucradas en acciones misioneras y el resto, es decir entre 87 y 94 de cada 100, parecen no estar involucrados en actividades misioneras.

\section{Antecedentes del problema}

Algunas formas de proyectos en misionología son de corto, mediano o largo plazo, adicionalmente otras investigaciones indican la necesidad de involucrar a los jóvenes en esas misiones.

Luis Fernando Ortiz indica que existe necesidad de involucrar a los jóvenes en la acción misionera. Los principios presentados, en el Antiguo Testamento, se pueden aplicar para desarrollar en los jóvenes elementos de verdad, involucramiento, equipamiento y empoderamiento, no solamente para evangelismo sino también

miso misionero llegó a un más alto nivel el 2012 donde se registra que 13 tienen compromiso misionero. http://www. adventiststatistics.org/view_Summary. asp?FieldInstID $=2453047$ consultado el 25 de agosto de 2014. 
para reproducción. ${ }^{5}$ Es decir trabajo misionero. Elena de White aconseja que:

Tenemos hoy un ejército de jóvenes que puede hacer mucho si es debidamente dirigido y animado. Queremos que nuestros hijos crean la verdad. Queremos que sean bendecidos por Dios. Queremos que participen en planes bien organizados para ayudar a otros jóvenes. Prepárense todos de tal manera que puedan representar debidamente la verdad, dando razón de la esperanza que hay en ellos, y honrando a Dios en cualquier ramo de labor donde estén calificados para actuar. ${ }^{6}$

Según Tadeu de Jesús e Silva Filho las actividades misioneras como distribuir folletos, dar estudios bíblicos están entre el 1,7 y 3,1\% de las preferencias de las actividades de los jóvenes? ${ }^{7}$ Estos

${ }^{5}$ Luis Fernando Ortiz, "Hacia una teologia del ministerio joven y la praxis en la iglesia local.pdf" (Andrews University, 1997). Pp. 2.

${ }^{6}$ Elena G. de White. Boletín de la Asociación General 5: No2, 29, 30; 24 de enero de 1893.

${ }^{7}$ Tadeu de Jesús e Silva Filho, Relato- datos indican la necesidad de desarrollar programas que ayuden a inmiscuir a los jóvenes en actividades misioneras con enfoques más participativos y desafiantes.

El proyecto Caleb se inició en la Unión Noreste de Brasil con Odailson Fonseca, con el objetivo de movilizar a los jóvenes en la tarea misionera. En el Perú se inició el 2009, involucrando a 1800 jóvenes logrando 1,860 bautismos; en el 2010 se involucraron a 5,462 que bautizaron a 3462 personas y entre el 2011 y 2012 fue la explosión de este proyecto, porque por primera vez en la historia del Perú se movilizó a más de 15,000.

Esta investigación es importante, porque es el primero en realizarse de manera exploratoria y correlacional, y su aporte se hace palpable en un instrumento que ayuda a medir el compromiso misionero y Misión Caleb, también aporta elementos teóricos al desarrollo bíblico-teológico de estas variables, finalmente, en cuanto a las razones prácticas, las recomenrio da pesquisa ministerio joven da Igreja Adventista Do Sétimo Día (Brasilia, 2009).p. 63. 
daciones de esta investigación ayudará en futuras intervenciones de la aplicación de Misión Caleb o programas similares en cualquier territorio.

\section{Marco Bíblico-Teológico}

\section{Compromiso misionero}

En esta sección se abordarán cuatro tópicos concernientes al tema: ¿qué es compromiso misionero?, la Biblia y el compromiso misionero, Elena G. de White y el compromiso misionero, y el compromiso misionero en la actualidad.

¿Qué es compromiso misionero?

La definición de compromiso misionero se definirá por separado. La Real Academia Española indica que "compromiso" está relacionado con obligación contraída, promesa de realizar algo o convenio; mientras que "misión" es la acción de enviar para realizar un trabajo específico. ${ }^{8}$ Entonces, de

${ }^{8}$ Real Academia Española, "RAE", Real Academia Española, http://es.wikipedia.org/wiki/Misi\%C3\%B3n (consultado: 17 de Octubre, 2014); Wikipedia, una manera general, se podría indicar que compromiso misionero significa una obligación contraída con alguien para realizar un trabajo específico. Según McGavran, misión, en el ámbito religioso, posee un propósito específico que describe la actividad de proclamar las buenas nuevas de Jesucristo y persuadir a hombres y mujeres para que lleguen a ser sus discípulos y miembros responsables de su iglesia. ${ }^{9}$ Compromiso misionero significa aceptar el mandato $\mathrm{u}$ obligación que tiene el cristiano de ganar almas para Cristo.

En la Biblia no se indica directamente la definición de compromiso misionero, sin embargo, tanto en el Antiguo como en el Nuevo Testamento se presentan actividades que implican compromiso misional. En el A. T. las actividades eran de forma centrí$\operatorname{peta}^{10}$, mientras que en el NT de

"Wikipedia", Wikipedia, http://lema.rae. es/drae/?val=misión (consultado: 17 de Octubre, 2014).

${ }^{9}$ Donald A. McGavran, Understanding Church Growth (Grand Rapids, Michigan: Eedermans, 1990), 20.

${ }^{10}$ Israel, como nación, era el ente escogido por Dios para proclamar el men- 
forma centrífuga ${ }^{11}$.

Compromiso Misionero en el Antiguo Testamento

Entendiendo que el compromiso misionero, en el A.T., estaba relacionado con llamar la atención de las demás naciones para que sigan a Dios por medio del ejemplo que el pueblo de Israel daba a las demás naciones (Deu 4:6-8). Así el compromiso misionero puede ser percibido en la vida de Abraham, cuando aceptó el llamado divino de ir a donde Dios lo mandara y de formar un gran pueblo que sería una bendición para todas las familias de la tierra (Gn 12:2, 3). Sin embargo, la mayor expresión de la actitud misionera de Abraham es percibida en Génesis 13: 3 , 4 , donde se describe que en todo

saje de salvación al mundo, por lo que las naciones aledañas, al ver su fidelidad a Jehová, debían proceder al arrepentimiento y búsqueda del Dios verdadero (Gn 12:2, 3; 13:3, 4).

${ }^{11} \mathrm{Se}$ le encomienda al Israel espiritual a cumplir la gran comisión que Israel, como nación, dejó de lado. Ahora el centro del evangelio ya no era Israel como nación, sino todo el mundo, porque Dios establecería una iglesia mundial (Mt 28:19-21; 1 P 2:9). lugar que pasaba Abraham en su viaje a la tierra de Canaán, él edificaba un altar con el propósito de que toda persona que pasara por aquel lugar conociera que existía un Dios verdadero en los cielos a quien se debía adorar.

El llamado de Dios, al pueblo de Israel, ha sido para que ellos puedan ser santos (Lev 11:44, 45; $19: 2 ; 20: 7,26)$. Por esa razón los profetas trataban de llevar a los integrantes del pueblo de Dios a ser el ejemplo que Dios quería de manera permanente. Algunos profetas no deseaban cumplir con la misión que Dios les encomendó, especialmente con personas que no eran parte del pueblo de Dios, así el profeta Jonás se reveló ante la orden misionera dada por Dios, se podría decir que su actitud mostraba la falta de compromiso misionero, sin embargo, los actos de amor de Dios permitieron que los ninivitas escucharan y se arrepintieran de sus malos caminos; así, aunque el profeta se reveló contra la orden de Dios, cumplió con la misión salvadora de Dios (Jonás 3). 
El compromiso misionero está más allá de las palabras, tiene que ver con el estilo de vida, así el compromiso misionero de Daniel y sus amigos fue demostrado por medio de mantener sus costumbres de salud ordenadas por Dios y evitaron las costumbres paganas de los babilonios.

Algunas de las respuestas positivas al llamado de Dios, a la actividad profética, son la del profeta Isaías, cuando su respuesta fue: “¡Aquí estoy: envíame!” (Is 6:8). A partir de entonces, la única tarea de Isaías fue llevar el mensaje divino de amonestación y esperanza a Israel; otro profeta con un llamado especial fue Jeremías quien estaba comprometido con la misión de que el mensaje sea conocido y aceptado por su pueblo y por otras naciones por medio del pueblo de Dios (Jr 1:5-10).

Así como se ha mencionado el compromiso misionero, en el Antiguo Testamento, tiene que ver con cumplir los mandatos de Dios como un pueblo especial que atraigan a los demás pueblos hacia Dios, así se podía cumplir con el compromiso misionero centrípeta.

Compromiso misionero en el Nuevo Testamento

El nuevo testamento también tuvo presente el compromiso misionero, pero desde una óptica centrífuga, es decir, compartir el evangelio a todo el mundo $(\mathrm{Mr}$ 16:15). Esto es notorio a través del llamado al ministerio que Cristo hizo a sus discípulos. Él los llamó a cambiar de función, de ser pescadores de peces a ser "pescadores de hombres" (Mt 4:19), de recaudadores de impuestos a discípulos seguidores del maestro Divino. Pero este compromiso misionero, que Dios demandaba, no era un mero compromiso sencillo, simple o efímero, sino que requería de un deseo voluntario de dejar muchas cosas de lado, por causa de la predicación del evangelio. Jesús dijo: "El que quiera seguirme, que renuncie a sí mismo, cargue con su cruz y sígame. Pues el que quiera asegurar su vida la perderá, pero el que sacrifique su vida por causa mía, la hallará” (Mt 16:24). Frente a esta declaración divina, 
es preciso afirmar que toda persona que decidía seguir a Jesús no debía y no debe vivir en un letargo espiritual, sino que debe estar comprometido con la gran comisión, demostrando que Cristo ocupa el primer lugar en su vida.

Cada nuevo converso que aceptaba a Cristo, como su salvador personal, se transformaba en un nuevo discípulo que Dios tomaba para que cumpla con la predicación de su evangelio, tal y como ocurrió con sus doce discípulos y con los setenta que envió a predicar (Mr 3:14; Lc 10:1).

Sin embargo, el discípulo de Cristo, al aceptar el gran desafío de la predicación del evangelio, no iba a cumplir su misión solo comprometiéndose con Dios, sino sabiendo que su mensaje era la luz verdadera que iluminaba al mundo (Jn 1:9), y que el Señor mismo lo ayudaría a que su misión se haga realidad (Mr 16:20).

Para una persona que estaba comprometida con la misión, no había limitaciones geográficas que interfirieran el cumplimiento de la gran comisión. Por el contra- rio, Cristo abrió las fronteras de las naciones para que su evangelio sea difundido, primero en casa (Jerusalén), luego a los enemigos y vecinos (Samaria), y por último a todo el mundo (Hch 1:8), nunca solos, siempre con el Espíritu Santo.

En realidad, Cristo aperturó las fronteras geográficas para el evangelio, latiendo este en el pensamiento y las emociones de los discípulos impulsaban la voluntad de los discípulos a cumplir con la actividad misionera. No podía callar el mensaje que había visto y oído (Hch 4:20), tal y como lo hicieron Pedro y Juan ante el sanedrín, y Pablo en Corinto (Hch 18:9), porque ellos sabían que el evangelio de Cristo era poder y riqueza de Dios para salvación a todos los que creyesen en él (Ro 1:16; Ef 3:8).

La motivación de los apóstoles de Cristo, para estar comprometidos en la obra de Dios, no era el deseo de gloriarse del evangelio, sino la necesidad imperiosa de proclamar el evangelio, así Pablo dijo: "¡Pobre de mí si no anuncio 
el Evangelio!” (1 Co 9:16). Esta declaración implica cumplir el mandato de difundir el mensaje, no como una obligación sino como una necesidad de salvar al mundo, que era preciso no igno$\operatorname{rar}$ (Hch 22: 14-15, 21; Ro 11: 13; 15: 16; Ef 3: 7-8) porque si lo ignoraban no podría tener paz o el favor de Dios.

Además, a través de lo mencionado en Efesios 3:8, se puede notar aún más que para Pablo el estar comprometido con la misión, no era una obligación sino "gracia" de Dios (Ef 3:8). Es decir, era un favor, bondad o privilegio ${ }^{12}$ que Dios le estaba concediendo. De la misma manera, en la actualidad, la persona que está comprometida con la misión, debe consi-

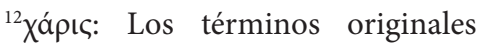
significan "favor" o "bondad", especialmente si no ha sido ganada ni merecida. El término hebreo se encuentra con frecuencia en el AT en frases como: "Halle yo ahora gracia en tus ojos" (Gn. 30:27; Ex. 33:13). Tales expresiones se usan repetidamente como una fórmula de cortesía al dirigirse a Dios o a una persona; Véase en: Siegfried Horn, ed., Diccionario bíblico adventista del séptimo día (Buenos Aires: Asociación Casa Editora Sudamericana, 1995), s.v. "jaris", 153. derar como un privilegio divino el difundir el mensaje de salvación a todo el mundo.

Finalmente, el texto que demuestra la plenitud del compromiso misionero en el Nuevo Testamento es Mateo 28:19. Dios ordena a sus hijos estar comprometidos en el trabajo misionero. Asimismo, este texto muestra las implicancias del compromiso misionero: hacer discípulos, después bautizar y enseñar cumpliendo todo lo que Cristo enseñó en esta tierra.

\section{Elena G. de White y el compro- miso misionero}

Elena G. de White, en su libro Ministerio de la bondad, hace un llamado a cumplir y proseguir la comisión de Cristo, aquella obra que él comenzó aquí en la tierra. Asimismo, ella asume que la Iglesia ha sido privilegiada y fue organizada con el propósito de cumplir dicha comisión. ${ }^{13}$

Por otro lado, para White el cumplimiento de la gran comisión no solo es un privilegio y la razón de existir de la Iglesia, sino tam-

${ }^{13}$ Ministerio de la bondad, 118 . 
bién al haber sido dada aquella comisión a los apóstoles de ir a todo el mundo y predicar el evangelio, demuestra la extensión de la obra, ameritando una responsabilidad o compromiso misionero de cada uno de los miembros de la Iglesia, con el propósito de que la prerrogativa divina sea efectuada en esta tierra. ${ }^{14}$

También enfatiza que las iglesias están llamadas a preparar sus misioneros y, de esta forma, contribuir al cumplimiento de la gran comisión. ${ }^{15}$ Esto demuestra que toda iglesia debe y deberá vivir un serio compromiso misionero, preparando y comprometiendo a sus miembros en la tarea de la predicación del evangelio.

En una carta, dirigida a la facultad de Loma Linda, la señora White afirma que el deber de esta institución era preparar estudiantes para servir a su prójimo,

${ }^{14}$ Elena G. de White, Testimonios selectos (Buenos Aires: Asociación Casa Editora Sudamericana, 1996), 3:344,45.

${ }^{15}$ Elena G. de White, Testimonios para la iglesia (Buenos Aires: Asociación Casa Editora Sudamericana, 1996), 5:368. buscando que profundicen en la Palabra de Dios, y que adapten las prácticas de sus vidas a las verdades de la Palabra. Y que la educación que en ella se impartiera, calificara a jóvenes y señoritas consagrados para vivir en armonía con la gran comisión. ${ }^{16}$ Es decir, en el cumplimiento de la gran comisión no solo está inmersa la Iglesia, sino también cada una de las instituciones que ella administra, siendo este el caso del área educativa, donde en las universidades y centros educativos adventistas deben de prepararse estudiantes comprometidos con la labor misionera por precepto y ejemplo, al servicio de su prójimo para el cumplimiento de la misión.

Asimismo, Elena G. de White continúa mencionando en su libro El ministerio médico, que como el Padre envió a su Hijo unigénito, así Cristo enviaba a ellos (sus hijos), sus discípulos, como sus obreros médico-misioneros para realizar una comisión elevada y

${ }^{16}$ Carta 196, 1908; Véase en: Elena G. de White, El ministerio médico (Buenos Aires: Asociación Casa Editora Sudamericana, 1996), 98. 
santa. ${ }^{17}$ Esto demuestra aún más la amplitud del compromiso misionero, un compromiso dirigido no solo a la feligresía de la Iglesia, sino también a los profesionales formados en las instituciones educativas adventistas, con el mismo propósito: estar comprometidos en cumplir una labor elevada y santa.

Según White, la persona que está inmersa en el compromiso misionero obtiene una mejor vida espiritual, porque crece en la gracia y en el conocimiento divino; y como consecuencia obtiene gozo, éxito y gloria cuando atiende al llamado del Maestro: "Heme aquí, envíame a mí” (Isaías 6:8). ${ }^{18}$ De esta forma, mostrando su carácter de servicio misionero. Finalmente, ella concluye que Dios conoce con qué fidelidad y espíritu de consagración cada uno de los miembros de su Iglesia cumple su misión, por tal motivo, "no hay lugar para los perezosos” en la obra del cumplimiento de la gran comisión. ${ }^{19}$ Es decir, toda persona que

${ }^{17}$ White, El ministerio Médico, 98.

${ }^{18}$ Elena G. de White, Mensajes selectos (Mountain View, California: Publicaciones Interamericanas, 1986), 2:191.

${ }^{19}$ White, Testimonios para la iglesia, 5:549. está comprometida en la labor misionera, desarrolla su fe, conoce aún más a Dios. Reflejando, en su vida, fidelidad y consagración hacia su Creador, obteniendo como resultado una iglesia saludable y libre de perezosos.

En conclusión. Para Elena G. de White, el compromiso misionero es el privilegio y la razón de existir de la Iglesia Adventista del Séptimo Día, que debe ser realizado de manera responsable y seria, preparando y comprometiendo a sus miembros para el cumplimiento de la gran comisión. Sin embargo, no solo la Iglesia, como entidad eclesiástica, debe estar inmersa en este asunto de índole alto y santo, sino también las diferentes instituciones pertenecientes a ella, compartiendo el mismo propósito, terminar la predicación del evangelio. Al hacerlo así, se obtendrá una iglesia saludable, con miembros fieles y consagrados a su Dios.

\section{El compromiso misionero en la actualidad}

En la actual teología aplicada, existe el movimiento de crecimiento de Iglesia caracterizado 
por promover los principios de crecimiento de Iglesia mediante la Escuela de Misión Mundial de Fuller, libros, conferencias, servicios de consultores, seminarios e institutos de investigación en crecimiento de Iglesia. La motivación básica de este movimiento está basada en: (1) obediencia a la gran comisión de Jesús (Mt 28:18-20); (2) el optimismo y la voluntad de Dios de alcanzar con el evangelio a todas las personas; y (3) la urgente necesidad de dirigir todos los recursos disponibles para alcanzar a todos los pueblos no alcanzados de la tierra. ${ }^{20}$ En síntesis, cada uno de los principios de crecimiento de Iglesia están relacionados al compromiso misionero de los miembros de la Iglesia.

Peter Wagner presenta seis axiomas de crecimiento de Iglesia, siendo uno de ellos, que "los miembros deben querer que la Iglesia crezca y estar dispuestos a

${ }^{20}$ Daniel Julio Rode, Fundamentos de crecimiento de iglesia (Libertador San Martín, Entre Ríos, Argentina: Editorial Universidad Adventista del Plata, 2008), 35. pagar el precio". ${ }^{21}$ Esto quiere decir que, según este escritor, para que pueda existir crecimiento de Iglesia es necesario un compromiso misionero total por parte de sus miembros. Asimismo, para los teólogos modernos como Pedro Larson y McGavran, cuando una Iglesia crece es por la fidelidad de sus miembros como el compromiso misionero, pero con otro nombre, ${ }^{22}$ debido a que ambos son reflejo del crecimiento de la Iglesia.

${ }^{21}$ C. Peter Wagner, Your Church Can Be Healthy (Nashville, Tennessee: Abingdon Press, 1979), 24-28.

${ }^{22} \mathrm{La}$ similitud entre el factor del compromiso misionero con la fidelidad a Dios como generadores del crecimiento de Iglesia se puede notar en lo que para Larson demanda fidelidad a Dios. Para este escritor, la fidelidad a Dios demanda: (1) Proclamar el evangelio: esto es en base a la gran comisión de Cristo, impulsados por el Espíritu Santo, (2) Encontrar a los perdidos, (3) Recoger y alimentar a los creyentes, (4) Multiplicar iglesias, (5) Relacionarnos con el mundo. Ante este concepto de fidelidad a Dios por parte de Larson, se puede afirmar que tanto fidelidad a Dios como compromiso misionero pueden complementarse o ser lo mismo. Véase en: Pedro Larson, Crecimiento de la iglesia: una perspectiva bíblica (El Paso: Casa Bautista de Publicaciones, 1989), 126, 27. 
Por otro lado, al estar inmersa la fidelidad a Dios en la mayordomía, y siendo que esta se la relaciona con el compromiso misionero, Peter Wagner hace referencia al apóstol Pablo, alegando que él se consideraba a sí mismo como "mayordomo de los misterios de Dios" (1 Co 4:1), por lo tanto, también Dios le había hecho mayordomo de su evangelio, como ahora se le ha concedido a su Iglesia. ${ }^{23}$ Es por ello, que se puede afirmar que el compromiso misionero, también es reflejo de la calidad de mayordomía de los miembros de una Iglesia, debido a que Dios les ha encomendado ser fieles mayordomos de su evangelio (Mt 28:19-21).

Finalmente, Rick Warren afirma que una genuina madurez espiritual, incluye usar los dones y talentos en servicio a otros y compartir el evangelio con muchas personas. ${ }^{24} \mathrm{Si}$ bien es cierto, el

${ }^{23}$ C. Peter Wagner, Su iglesia puede crecer: siete características de una iglesia viva (Terrassa: Editorial CLIE, 1980), 45.

${ }^{24}$ Rick Warren, The purpose Driven Church: Growth Without Compromising Your Message \& Mission (Grand Rapids, Michigan: Zondervan Publishing House, 1995) 340 . autor no relaciona al "compromiso misionero" con lo que para él significa "genuina madurez espiritual", pero permite entender que el "compromiso misionero" está inmerso en la "madurez espiritual”, por ello, Warren asume que "el desarrollo espiritual ocurre por participar en todos los cinco propósitos de la Iglesia", ${ }^{25}$ siendo uno de ellos el evangelismo. Es decir, una persona que está comprometida con el trabajo misionero, obtiene, como consecuencia, que su fe se desarrolle o madure.

En síntesis ante lo mencionado en esta sección, el compromiso misionero es un factor importante para que exista crecimiento de iglesia, como muestra de fidelidad a Dios y de una calidad de mayordomía. Y como consecuencia de ello, obtener una madurez y desarrollo de la fe.

\section{Descripción de información ge- neral de los resultados}

Los participantes en esta inves-

${ }^{25}$ Rick Warren presenta cinco experiencias que una iglesia debe pasar para madurar o desarrollar su fe: adoración, comunión, estudio de la Biblia, evangelismo y ministerio; Véase en: Ibíd. 
tigación se encontraban entre 12 y 49 años, sin embargo, el mayor porcentaje se encontraba entre los rangos de 19 a 36 años sumando un total de $52 \%$, de los cuales el $32,8 \%$ pertenece al rango de 19 a 24 años, el 17,6\% pertenece al rango de 25 a 30 años y, finalmente, el $12,6 \%$ pertenece al rango 31-36 años de edad. En relación al lugar de procedencia del área rural en un $21,1 \%$, mientras que los provenientes de la ciudad era el 78,6\%. En cuanto a género el masculino era un $53,7 \%$ y de sexo femenino un $46,3 \%$.

El estado civil de los participantes indica que el 0,9\% es viudo, el 2,3\% vive en unión libre, otro porcentaje similar indica que son divorciados, sin embargo, el 9,7\% indica que son solteros próximos a casarse. Otro porcentaje, tal vez uno de los más altos, indican que son casados, es decir el 23,8 \% los cuales son aproximadamente unas 81 personas; finalmente la tabla muestra que el $61 \%$, es decir, el más alto de los datos son solteros con planes de matrimonio. Los datos revelan que los solteros son los que más participan en "Misión
Caleb”, seguramente por su espíritu emprendedor y buscan vencer retos, además de la amistad de los jóvenes puede estar el compromiso misionero que ya tienen desde que vienen de sus iglesias. La tabla 6 de ocupación cotidiana de los participantes, de "Misión Caleb", muestra que el 9,4\% se dedica a estudios de nivel secundario, el $5,9 \%$ se dedica a laboras de casa, otro tipo de labores son realizadas por el $4,4 \%$, por otro lado, el $38,4 \%$ indica que su ocupación cotidiana es el trabajo, mientras que para el mayor porcentaje que es el 41,9\% dice que el estudio en la universidad es su actividad más recurrente.

En relación al número de Veces que los investigados han participado en "Misión Caleb" el 3,2\% participó cinco veces, el 7,6 lo hizo durante cuatro oportunidades, el $12 \%$ durante tres veces, el 22,6\% lo hizo, por lo menos, en dos oportunidades y, finalmente, el 21, 7 \% lo hizo, por lo menos, una vez. Por otro lado, el 32,8 \% participó por primera vez en "Misión Caleb", es decir, uno de cada tres son nuevos. Los datos revelan que el 67,2\%, 
es decir la mayoría de los participantes han regresado entre una a cinco veces para participar de este programa evangelístico, por otro lado, una tercera parte son nuevos.
Compromiso misionero antes y después de participar en Misión Caleb

Misión Caleb es una actividad de trabajo evangelístico de

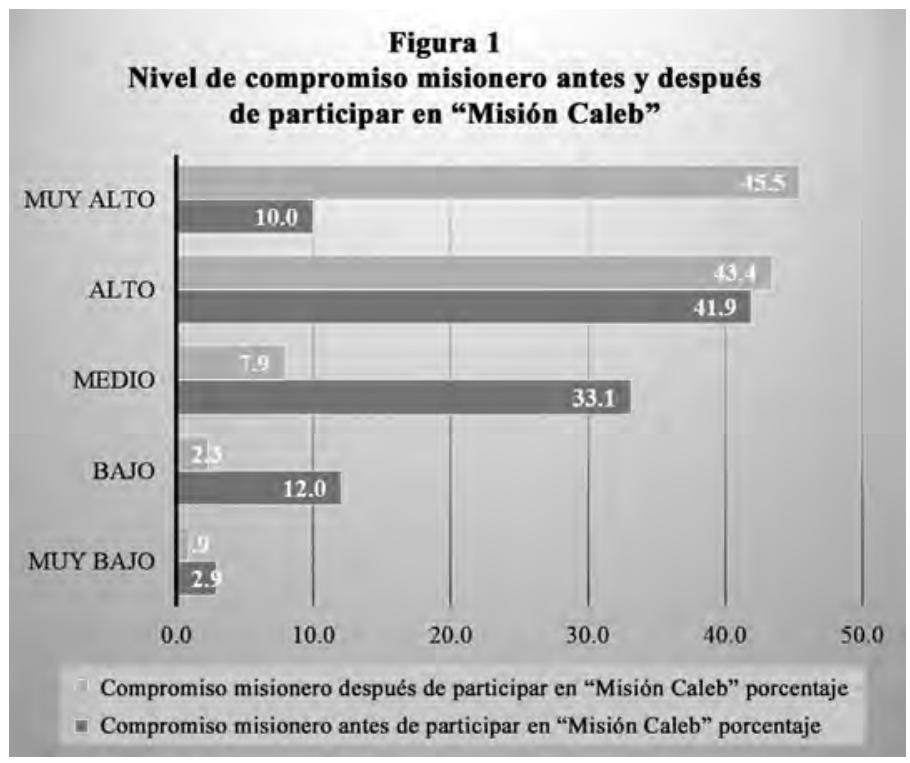

misiones a corto plazo y se puede apreciar los resultados en el compromiso misionero de sus participantes.

En la figura 1 indica que aquellos que iniciaron con un nivel "muy bajo" fue el 2,9 \%, después de Caleb ese nivel descendió a un $0,3 \%$; los que estaban en el nivel "bajo" era el $12 \%$, después de Caleb ese nivel descendió a un 2,3 $\%$; en el nivel "medio" antes de Caleb estaba el 33,1 \%, descendió hasta un 7,9 \% después de Caleb; y los de un nivel "alto" antes de Caleb el 41,9 \% aumentó al 43,4 $\%$ después de Caleb; y por último, los que se encontraban en un ni- 
vel "muy alto" antes de Caleb, un $10 \%$, al culminar Misión Caleb creció hasta un 45,5\%.

Tomando en cuenta los datos anteriores, se puede concluir que hubo un incremento significativo en compromiso misionero des- pués de "Misión Caleb" porque, por ejemplo, el nivel "muy alto" creció un 35,5\%, mientras que el nivel "alto" tuvo un crecimiento de un $2 \%$, después de "Misión Caleb".

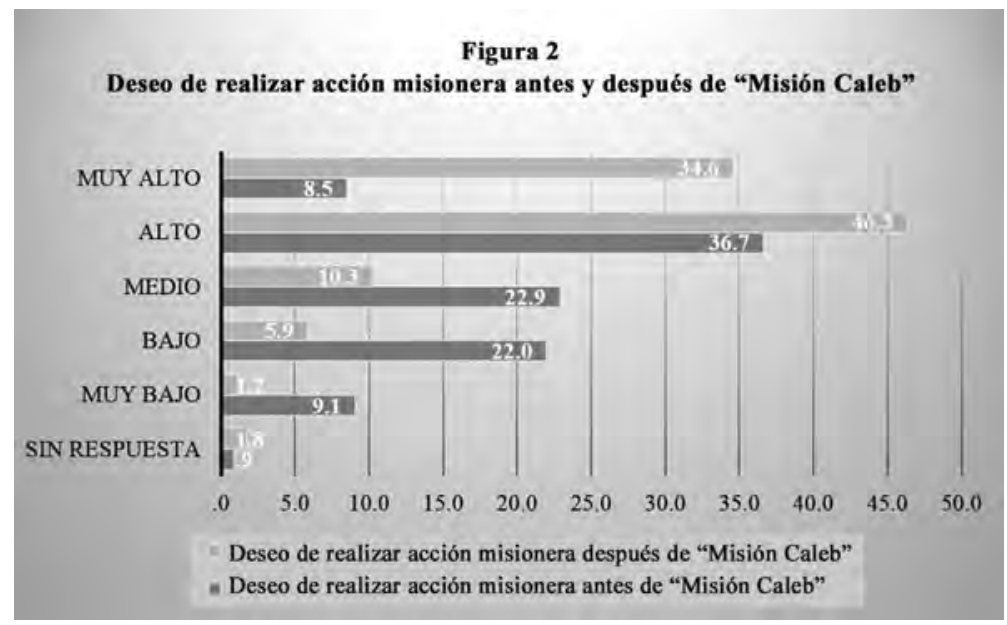

En la figura 2 se muestra el nivel de "deseo de realizar acción misionera". Aquellos que tenían un nivel de deseo "muy bajo" de acción misionera representa el 9,1\% (equivalente a 31 personas), al salir desciende hasta un 1,2\% (4 personas); los de nivel "bajo" representan el 22\% (equivalente a 75 personas), al finalizar descien- de hasta un 5,9\% (20 personas); los de nivel "medio" representan el $22,9 \%$ (equivalente a 78 personas), al salir desciende hasta un 10,3\% (35 personas); en contraste con aquellos de nivel de deseo "alto" que al inicio representa solo el $36,7 \%$ (equivalente a 125 personas), y crece hasta un $46,3 \%$ (158 personas); y, por último, 
quienes participaron con un nivel de deseo "muy alto" representa el $8,5 \%$ (equivalente a 29 personas), al culminar crece hasta un $34,6 \%$ (118 personas).

Por lo tanto, se puede concluir que la gran mayoría (el 59,4\%) de los participantes no realizaban actividad misionera, sin embargo, después de participar hubo un incremento sorprendente en esta actividad, siendo que el 35,7\% (equivalente a 122 personas) están en los niveles "alto" y "muy alto" en acción misionera.

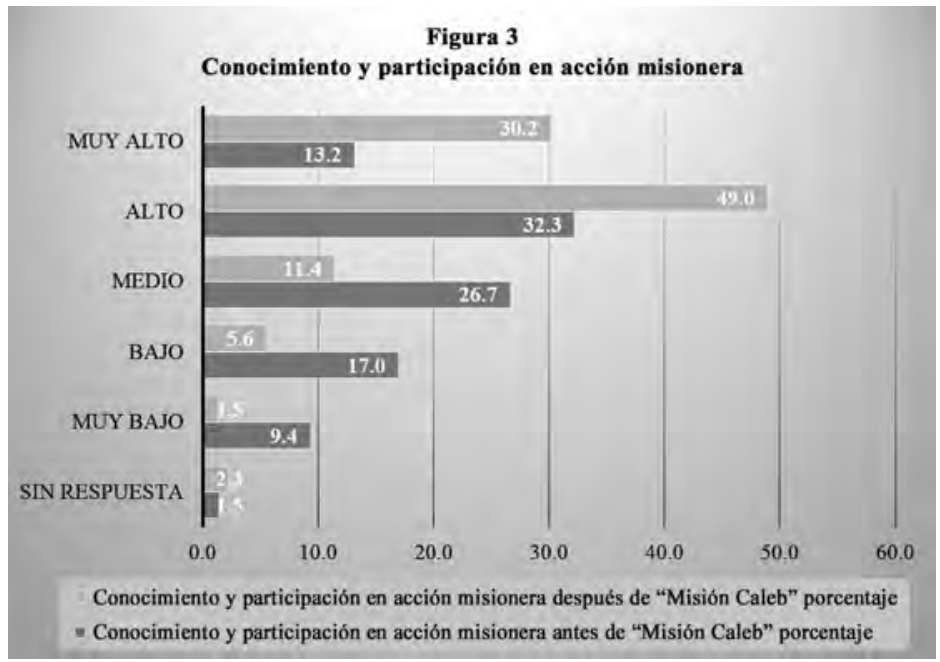

La figura 3 indica el nivel de "conocimiento y participación en acción misionera”. Aquellos que tenían un nivel "muy bajo" de conocimiento representa el 9,4\% (equivalente a 32 personas), al salir desciende hasta un 1,5\% (5 personas); los de nivel "bajo" representan el 17\% (equivalente a 58 personas), al finalizar descien- de hasta un 5,6\% (19 personas); los de nivel "medio" representan el 26,7\% (equivalente a 91 personas), al salir desciende hasta un $11,4 \%$ (39 personas); en contraste con aquellos de nivel "alto" que al inicio representa al 32,3\% (equivalente a 110 personas), y crece hasta un 49\% (167 personas); y por último, quienes participaron 
en Caleb con un nivel "muy alto" representando al 13,2\% (equivalente a 45 personas), al culminar la misión crece hasta un 30,2\% (103 personas). 186-54.6\%/115 pasa $-71 / 20.8 \%-33.8 \%$ desciende.

Por lo tanto, se concluye que el 54,6\% (186 personas) antes de participar en la "Misión Caleb" su nivel de conocimiento y participación variaba entre un nivel "muy bajo", "bajo" y "medio". Al culminar esta misión en Cajamarca, el nivel de conocimiento y participación en acción misionera de 115 personas (equivalente al 33,8\%) sube hasta un nivel "alto" y "muy alto"; esto quiere decir que participar en "Misión Caleb" impacta en el conocimiento más práctico y estimula el deseo de la acción misionera en el creyente.

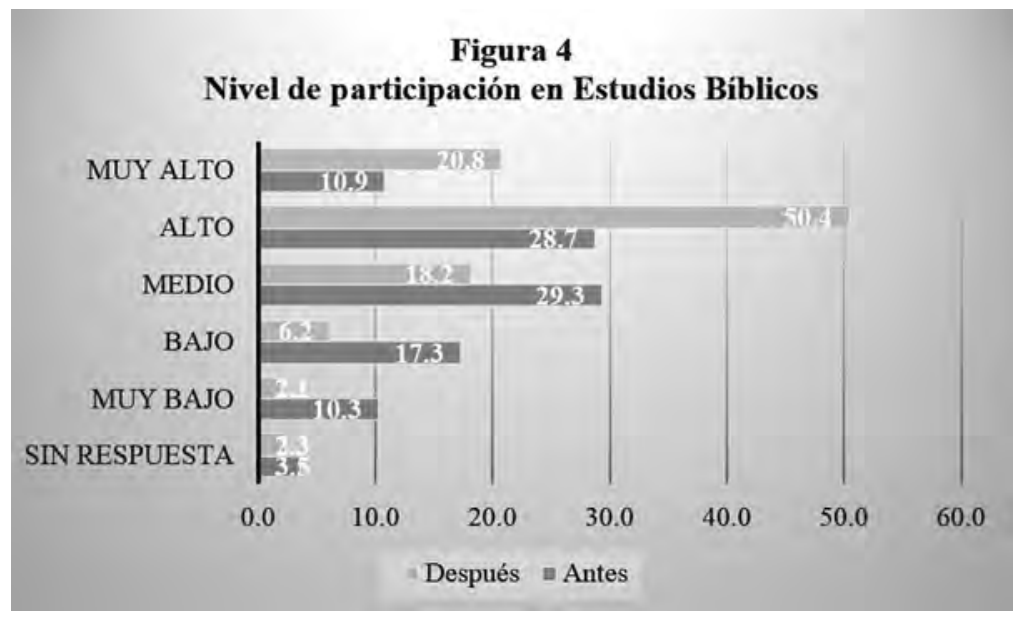

En la figura 4 se puede observar el nivel de participación que antes de Misión Caleb el nivel de participantes bíblicos se encuentran entre los niveles: muy bajo con un $10.3 \%$, bajo con un $17.3 \%$, medio con un $29.3 \%$ que suman un total de $56.9 \%$, sin embargo, después de participar en "Misión Caleb" se observa que está entre los niveles: alto con un $50.4 \%$ y muy alto con un $20.8 \%$ que da a un total de $82 \%$. 
Entonces, se puede concluir que el nivel de participación en estudios bíblicos antes de Misión Caleb es de un $56.9 \%$, sin embar- go después de haber participado en "Misión Caleb" el porcentaje de los que participan en estudios bíblicos se eleva a un $82 \%$.

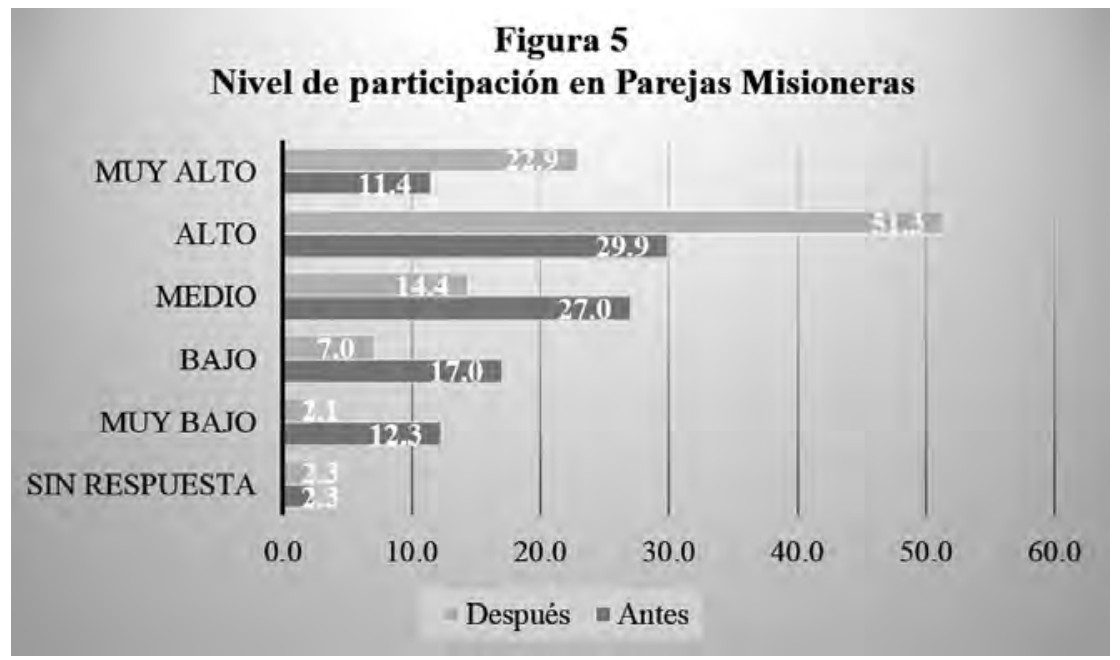

En la figura 5 se puede observar que el nivel de participantes en la estrategia misionera de parejas misioneras, antes de Misión Caleb, estaba en niveles muy bajo con $12.3 \%$, bajo con $17.05 \%$ y medio $27.0 \%$, sin embargo, luego de haber participado en Misión Caleb los niveles son: alto con $51.3 \%$ y muy alto con $22.9 \%$ haciendo un total de $74.2 \%$.
Entonces, se puede llegar a entender que los participantes de "Misión Caleb", en la estrategia de parejas misioneras, que antes el mayor porcentaje estaba ubicado en niveles bajos, elevaron su participación luego de "Misión Caleb" en la estrategia de parejas misioneras a $74.2 \%$. 


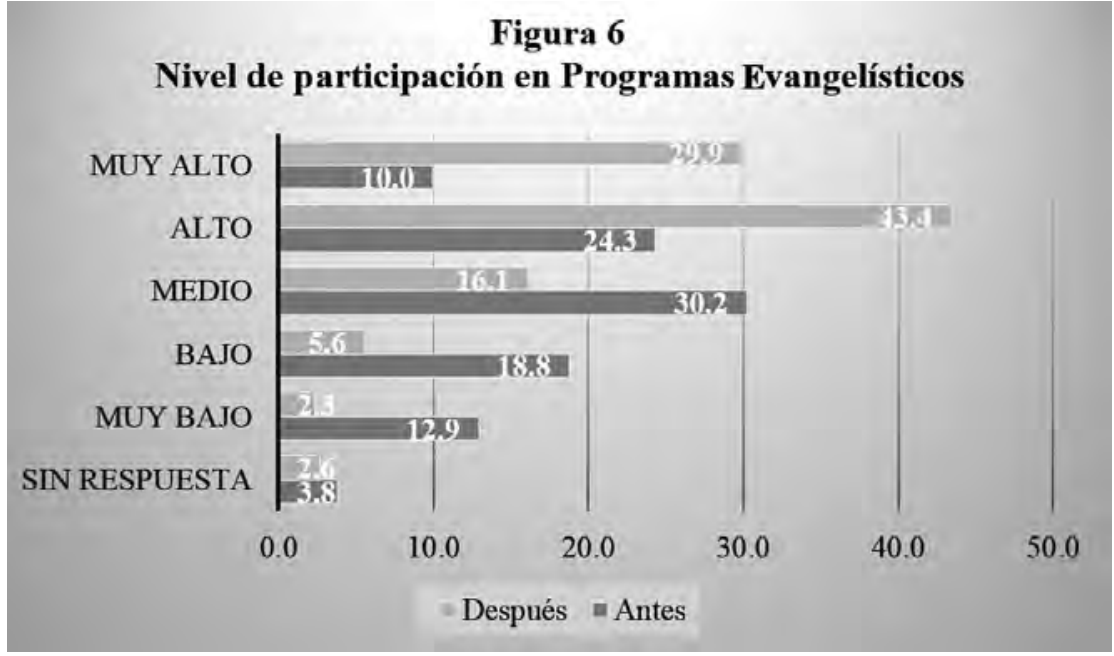

En la figura 6 se muestra el nivel de participación en programas evangelísticos antes y después de participar en "Misión Caleb", la figura muestra que, antes de "Misión Caleb", los participantes se ubican en niveles bajos en su mayoría, específicamente en el nivel muy bajo un $12.9 \%$, bajo el $18.8 \%$ y medio un $30.2 \%$; sin embargo, después de "Misión Caleb" se puede notar que la mayoría de los encuestados indican que se encuentran en niveles alto con un $43.4 \%$ y muy alto con 29.95 .
Entonces, se puede concluir que la participación en programas evangelísticos han sido impactados por la participación de miembros de la iglesia en "Misión Caleb" porque antes de "Misión Caleb" había un total de $61.9 \%$ en niveles bajos, pero luego de "Misión Caleb" un total de $73.3 \%$ se ubican en niveles altos. 


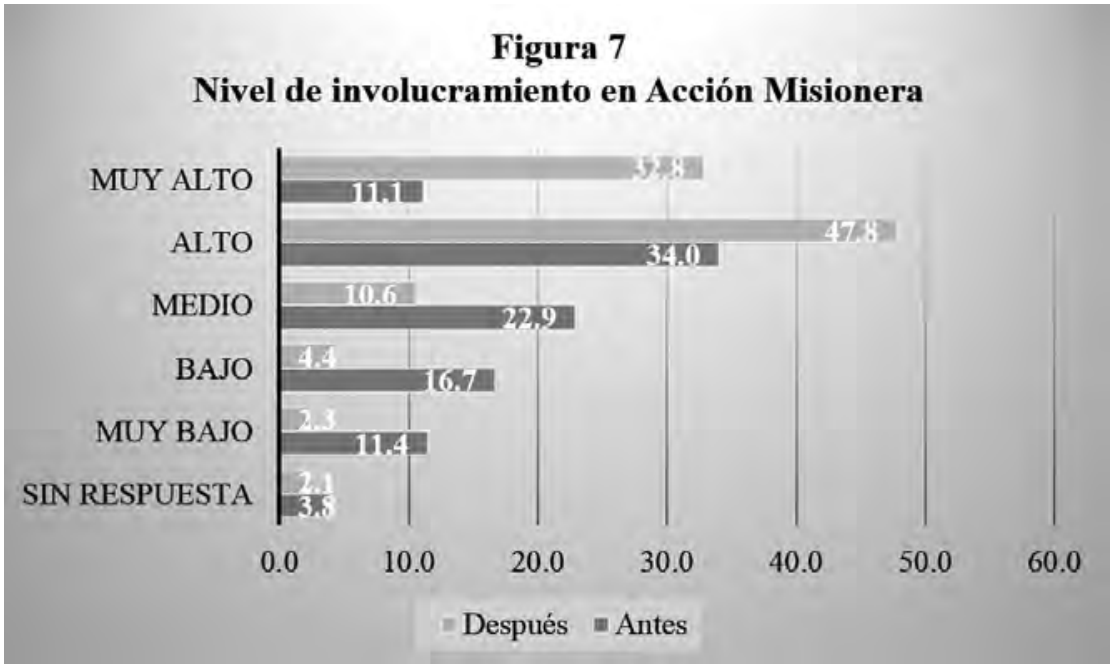

En la figura 7 se indica los resultados relacionados al involucramiento en acción misionera, antes y después de "Misión Caleb". Loa participantes muestran que antes de participar en "Misión Caleb" los miembros de iglesia estaban ubicados en niveles bajos, por ejemplo, en el nivel muy bajo estaba el $11.4 \%$, en el nivel bajo con $16.7 \%$, y en el nivel medio el 22.9\%, sin embargo, después de "Misión Caleb" el nivel en el que se ubicaron los participantes con un $47.8 \%$ en el nivel alto y el $32.8 \%$ en el nivel muy alto.
Entonces, se puede concluir que el hecho de participar en "Misión Caleb" tiene impacto en el nivel de involucramiento de los participantes en acción misionera, puesto que antes llegan a un $51.0 \%$, sin embargo, después de participar en "Misión Caleb" el $80.6 \%$ se ubica en niveles altos. 


\section{Figura 8}

Impacto de Misín Caleb en el compromiso misionero de los participantes

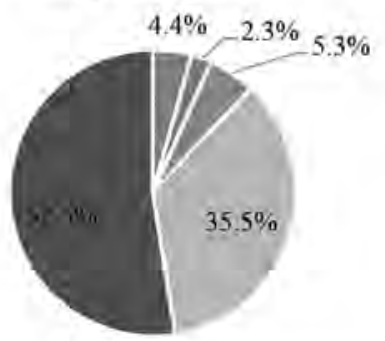

"No impactó "Algo = Poco "Considerablemente " Muchisimo

La figura 8 revela que el $88 \%$, es decir, 300 de una cantidad de

30341 de las personas que participaron en el proyecto Misión Caleb” señalan que han sido afectados considerablemente y muchísimo, respecto al compromiso misionero y que el $6,7 \%$ de los participantes señalan que su participación no afectó o impactó su compromiso misionero.

Por lo tanto, esto demuestra que el proyecto "Misión Caleb" ha afectado el compromiso misionero en la vida de los participantes, ya que el porcentaje elevado de los participantes indica que fueron afectados de manera considerable y muchísimo.

\section{Conclusiones}

Debido a que es una investigación exploratoria, se ha encontrado que la participación en Misión Caleb tiene efectos positivos en el nivel de compromiso misionero de los jóvenes.

Se identificó que la participación, en Misión Caleb, afecta en el deseo de enrolarse en actividades misioneras en sus iglesias, cuando vuelven a ellas. Se llega a esta conclusión porque antes de $\mathrm{Mi}$ - 
sión Caleb un $54,5 \%$ se situaba en niveles medios y bajos, mientras que después de participar en este programa solo un 19, 2 \% se quedó en esos niveles; además que estaban en niveles alto y muy alto, un $45,2 \%$ creció en $35.7 \%$, hasta llegar a $80.9 \%$ (ver figura 2).

Se determinó que los participantes en Misión Caleb fueron afectados en sus niveles de conocimiento y participación en actividades misioneras, porque antes de Caleb solo el 45,5\% se ubicaba en los niveles altos, mientras que luego de participar en Caleb esos mismos niveles sufrieron un cambio, porque se elevó en $33.7 \%$ hasta llegar a 79,2\%.

Se identificó que participar en Misión Caleb afecta en el nivel de participación para dar estudios bíblicos, porque solo el 39,6\% se identificaba en los niveles altos con esta actividad antes de Misión Caleb, pero después el $71,2 \%$ se identificaba en los niveles altos en esta actividad.

Se determinó que participar en Misión Caleb afecta positiva- mente la participación en la estrategia evangelística del trabajo en parejas misioneras porque, en los niveles alto y muy alto que antes de Caleb eran, se ubicaba un $41.3 \%$ de los participantes, este número se elevó, llegando a $74.2 \%$ en los mismos niveles.

Asimismo, se nota el efecto del programa Caleb en la participación de programas evangelisticos, porque en los niveles alto y muy alto antes de Caleb habían $34.3 \%$, luego de Caleb este nivel se elevó a $73.2 \%$, habiendo una diferencia del 39.9\%.

El efecto del programa Caleb se nota en el nivel de involucramiento en la acción misionera que antes de Caleb era 45.1\%, en los niveles alto y muy alto, mientras que después del programa Caleb llegaron a $80.6 \%$, verificándose una diferencia de casi un $35 \%$.

Los mismos participantes indicaron que el programa Misión Caleb afectó su compromiso misionero considerablemente y muchísimo en $35.5 \%$ y $52.5 \%$, respectivamente. 